\title{
Citizen E-Participation: Bringing the "E" to Facilitated Workshops
}

\author{
Mathis Poser \\ University of Hamburg \\ poser@informatik.uni-hamburg.de \\ Gerrit C. Küstermann \\ University of Hamburg \\ kuestermann@informatik.uni-hamburg.de bittner@informatik.uni-hamburg.de
}

\begin{abstract}
Citizen participation initiatives enable public decision-makers to integrate the knowledge and preferences of citizens into municipal planning processes at an early stage. To this end, workshops are frequently and recurrently utilized instruments, which foster the collaboration of citizens with public authorities and with one another. With the rise of ICT, e-participation has evolved as a strategic pillar in digital governance, but has not fully reached participation workshops yet. Establishing an integrated e-participation approach that combines traditional and e-participation instruments poses a challenge in practice. Therefore, we apply Collaboration Engineering to design and evaluate an e-participation workshop process, which incorporates theoretical and practical requirements, allows the seamless transfer of digitally generated input across instruments and process steps, and sustains a workshop execution by domain-specific practitioners. Evaluation results suggest promising potentials of the developed process design for increased idea elaboration and more effective documentation of workshopbased participation.
\end{abstract}

\section{Introduction}

The involvement of citizens in planning processes enables public decision-makers to include new, otherwise unconsidered perspectives, to improve the resulting solutions and their transparency and ultimately to legitimize these to the public $[17,47]$. Successful civic participation initiatives require a thorough design and implementation. This entails an appropriate exchange of information and ideas and a continuous dialogue between the stakeholders. To ensure this, it is crucial that participation takes place as early as possible in the decision making process and that various participation methods are systematically coordinated with respect to the defined participation objectives [9, 47]. The increasing adoption of information and communication technologies (ICT) for citizen participation (e-partici- pation) in recent years has also created new opportunities for strategic public involvement within the framework of digital governance [35, 48]. Analogue to traditional, non ICT-supported participation processes [28], a strategic integrated e-participation approach is under discussion [45]. Accordingly, the active participation of citizens, which is inherent in the concept of e-participation [34], requires the orchestration of eparticipation instruments to exploit the fruits of such e-participation initiatives [45]. To encourage successful integrative e-participatory decision-making processes, it seems necessary to examine, modify, and combine individual participatory techniques and tools to ensure their integrability into an e-participation strategy [40, 45]. In our research, we focus on facilitated workshops as frequently recurring interactive instruments in citizen participation processes. Facilitated workshops are commonly conducted at an early stage in the decision making process to involve citizens in order to collaboratively generate creative solutions to problems, for example in urban planning projects [5, 9, 22, 36]. Integrating workshops into a multiinstrumental e-participation strategy poses a challenge, though, if participation workshops are conducted "traditionally", without ICT support. That is, due to the stakeholders' opportunity to engage with several other instruments apart from workshops (e.g. online participation), the resulting media discontinuities impede the flow of generated information across instruments and data integration from various sources, which is a perquisite for an integrated e-participation strategy [1, 45]. Therefore, it is critical to understand how ICT can be integrated into traditional participation instruments [40]. Given this persistent problem, the research gap related to the topic of ICT-supported facilitated workshops in civic participation needs to be addressed. Correspondingly, our research question is:

How can ICT be integrated into traditional citizen participation workshops in order to be effectively and repeatedly applied in a multi-instrumental e-participation strategy?

Two interdependent objectives are deduced from this question: First, we aim to develop a blueprint by designing a workshop process, which specifies the integration of ICT in traditional citizen participation 
workshops. Moreover, due to their complexity, workshops impose high demands on facilitators, who need sophisticated skills to guide a group through the process [6, 31]. Therefore, we create a guideline for facilitators of such ICT-supported workshops with enforcing a systematic process design, which delivers satisfactory results with repeatable success. Second, by integrating ICT, our goal is to enable the most seamless transferability of the input generated during these workshops across instruments and processes.

The study is structured as following: First, our methodological approach with reference to Design Science Research (DSR) is explained. Second, the theoretical foundations are described. Subsequently, the development of the workshop process design is detailed. This is followed by the evaluation of the designed artefact. The study closes with a summary of the findings and contributions for practice and research.

\section{Methodological approach}

In our study, we utilize a Design Science Research approach to develop an artefact with reference to Hevner's three cycle view (relevance, design and rigor) [20]. In the relevance cycle, we identify a set of unsolved problems relating to the combination of specific traditional and e-participation instruments to establish and enhance an integrated e-participation approach. This problem identification in the application domain of civic (e-)participation defines our design activity - the development of a process design for ICT-supported facilitated workshops. In the rigor cycle, relevant information from citizen participation, eparticipation and Collaboration Engineering (CE) literature is extracted from the knowledge base to inform the design of our artefact. In the design cycle, we apply the Collaboration Process Design Approach (CoPDA) [23] to consider insights from CE literature to iteratively develop and evaluate our artefact. Following the design cycle, the knowledge base is expanded via the rigor cycle by adding prescriptive knowledge to literature [18]. In addition, the result of the design activity contributes via the relevance cycle to a solution to the identified problems in the practical environment.

\section{Theoretical background}

\subsection{E-participation}

The interdisciplinary field of e-participation has received much attention in recent years and has moved towards a more socio-technical system view that enables greater civic engagement in the public sector, not only in the political sphere [25, 33]. E-participation may be defined as "a participatory process that is enabled by modern information and communication technologies, includes stakeholders in the public decisionmaking processes through active information exchange, and thus fosters fair and representative policymaking” [45].

Based on the generally acknowledged participation spectrum by the International Association for Public Participation (IAP2), Tambouris et al. [41] specified the levels of e-participation: e-informing, e-consulting, e-involving, e-collaborating, and e-empowerment. In relation to this and considering the aforementioned definition, e-participation workshops, to our understanding, correspond to the more enhanced eparticipation levels (e-involving, e-collaborating) in which "ICTs support citizens in their willingness to collaborate with the government and between one another" [16]. However, the responsibility for the final decision ultimately remains with the public authorities [28]. Looking at the field of public participation from a technology-specific perspective, Wimmer [44] emphasized that e-collaboration "has a strong potential to support distinct participation areas and different stakeholders in the various stages of e-participation”, besides, Tambouris et al. [41] stressed the importance of Computer Supported Collaborative Work (CSCW) in the area of e-participation. However, technology-supported collaborative work has not fully reached civic participation workshops yet.

\subsection{Workshops in the scope of e-participation}

"Workshops are an effective means for achieving face-to-face interaction between citizens as they share in decisions that determine the quality and direction of their lives” [36]. In citizen participation workshops, solutions are principally co-produced. That is, public authorities and citizens must both provide information that is relevant to the others and participate actively in the collaboration [11]. The ideas generated in those workshops, however, are in many cases not developed beyond a basic initial description by the participants themselves. It is commonly up to the facilitators to summarize the contributions within the groups and to work out the specific ideas based on the interactions and discussions after the group sessions. For that, the facilitators usually take notes during the group sessions. In order to be capable of doing this, in addition to actively moderating the heterogeneous groups, providing technical assistance, and guiding the discussion to relevant issues [36], sometimes in a conspicuously emotional discussion, the tasks are usually distributed among several facilitators. Nevertheless, experience, a good memory and well-founded contextual 
knowledge are required to be able to educe the individual initial ideas veritably from the discussion. The level of detail must be such that other stakeholders (e.g. involved experts, public officials), who were not present at the workshop or in the particular group, can easily understand, concretize and develop ideas and solutions. This is particularly important, because many public participation processes are not formally specified. It is often up to the public official, who is accountable for a step in the process, to determine what is to be done next. Additional stakeholders involved in the process should therefore be adequately informed about past activities and the latest developments [30]. Thus, it seems desirable that the ideas collected within a workshop are structured and elaborated on more effectively and collaboratively by the participants themselves for effective further processing. This could be achieved through the deployment of ICT in workshops. Consequently, for the development of an e-participation workshop it is crucial to understand how ICT can be integrated into traditional participation instruments [40].

\subsection{Collaboration Engineering}

CE is an established approach to create and deploy repeatable collaboration processes for groups using collaboration techniques and technology for recurring high-value tasks $[8,23]$. The CE approach has been successfully applied in various domains (e.g. organizational and governmental) to design collaborative processes that involve ICT [2, 4, 42, 43]. The objective for collaboration engineers is to systematically design, define and document a sequence of steps, which are in accordance with a defined goal and require the collaboration of group members. The resulting reusable and transferable process enables experts in a target domain, so called practitioners, to execute collaborative work practices without ongoing support from a collaboration professional [38].

In adherence to the enhanced e-participation levels, the development of the e-participation workshop process has to ensure that citizens participate actively, work collaboratively and use the available ICT tools $[16,40]$. In addition, the workshop process should be efficiently replicable to constitute a valuable element within an e-participation strategy. As a frequently recurring instrument, the repeated workshop conduction should deliver a consistent level of outcome quality. Thus, the applicability and implementation success should be established through the systematic incorporation of relevant theoretical and practical knowledge. Hence, we applied CE as a suitable approach to develop the e-participation workshop process design.

\section{Collaboration Process Design Approach}

In this section, we describe the execution of the design cycle in our research by applying the CoPDA, which represents the central guideline in CE and supports the creation of collaborative processes. The CoPDA comprises the following five consecutive and iterative steps: 1) Task diagnosis, 2) Task decomposition, 3) Task-thinkLet choice, 4) Agenda building and 5) Design validation [23]. These steps are executed to derive a systematic, concise and detailed process design for the e-participation workshop. The steps one to four are described and implications for the emerging e-participation collaboration process are explained below. Step five, the evaluation of the design, is reported separately in Section five.

\subsection{Task diagnosis}

In the first step of the CoPDA, the requirements and constraints of the collaboration process are identified by consulting relevant stakeholders. This analysis covers the task, stakeholders, resources and practitioners involved [23, 43]. As a result, the goal of the process, the collaborative task and intermediate outcomes are defined. These outcomes are referred to as group products and represent tangible or intangible artefacts that need to be achieved by the group members [43]. According to this prescribed analysis, we specified practical and theoretical requirements in relation to the task, the group products and the overall goal of the collaborative e-participation workshop by consulting field experts and applicable literature.

Practical requirements: We used the methods of passive observation and informal conversations with experts at three different citizen participation workshops, conducted by municipal institutions and urban project development initiatives. The acquired insights pertain to the group characteristics (size and composition), the common sequence of activities and the duration of workshops. Furthermore, relevant group products were identified (see Table 1).

Theoretical requirements: In addition, we consulted literature to derive theoretical requirements. As already stated, e-participation necessitates the citizens to express their opinions and deliver creative input [5]. This form of active participation resembles the generation and elaboration of ideas and requires a creativityoriented problem solving approach. Therefore, we gained insights from creativity and innovation research. More precisely, we focused on group-level creativity and innovation due to the collaborative nature 
of the workshop. By definition, creativity is "the production of novel and useful ideas by an individual or small group of individuals working together" [3] and constitutes a sub-step of innovation, which additionally includes the implementation of ideas $[3,46]$. We employed the input-process-output model [19] in accordance to the approach of the comprehensive metaanalysis by Hülsheger et al. [21] to support the identification of the following group products:

- Idea generation within categories: Being primed to categories referring to a topic for idea generation and the exposure to homogenous ideas within a specific category increases the produced number of creative ideas [27, 32].

- Vision: A mental representation about the future state of a group process that defines the necessary actions and increases commitment among group members [21, 29].

- Goal interdependence: The individuals' goal attainment in a group depends on the goal achievement of the other members [12]. This interdependence provokes communication and collaboration among group members [21].

- Support for innovation: This created atmosphere supports the expression of novel ideas and tolerates erroneous attempts by group members [21].

- Team interaction: The communication and interaction in groups represents a source of information to the members, facilitates the formation of an understanding of one's role and promotes emergent group states [15, 21].

- Shared mental model: This knowledge structure evolves through group member interaction. It allows individuals to deduct expectations for the accomplishment of a collective task, to adapt their behavior according to the task and the actions of other group members [15, 24, 37].

- Participative safety: Participative safety ensures that every group member is involved in the decision-making process. In addition, an atmosphere of intragroup safety is created, which allows individuals to freely express their ideas [10, 21].

- Minority dissent: Group members publicly state opposing ideas, beliefs or attitudes, which prevent an alignment with the majority perspective and a dismissal of dissenting opinions [13, 14, 26].

A summary of these theoretically derived group products is presented in Table 1.

Goal of the process design: With the help of the aggregated practical and theoretical knowledge concerning the task, the group characteristics and the group products (see Table 1), we defined the overall goal of the collaborative e-participation workshop:

The objective of the process design is to structure the acquisition of precisely formulated, categorized and weighted ideas on different topics in a specific domain with a heterogeneous group of citizens divided into subgroups comprising at least 6 but not exceeding 10 members in a 95-minute workshop. The obtained ideas are then relayed to the administration to enrich a decision-making process.

Table 1. Practical $(P)$ and theoretical $(T)$ requirements for the e-participation workshop

\begin{tabular}{|c|c|c|c|}
\hline & \multirow{2}{*}{ Requirements } & \multicolumn{2}{|r|}{ Source } \\
\hline & & $\mathbf{P}$ & $\mathbf{T}$ \\
\hline \multirow{8}{*}{ 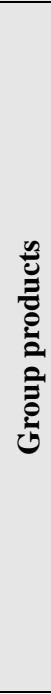 } & $\begin{array}{l}\text { Created vision and shared un- } \\
\text { derstanding of the procedure }\end{array}$ & $\mathrm{X}$ & $\begin{array}{c}X \\
{[21,29]} \\
\end{array}$ \\
\hline & $\begin{array}{l}\text { Created goal interdependence } \\
\text { and support for innovation by } \\
\text { explaining the task }\end{array}$ & $\mathrm{X}$ & $\begin{array}{c}\mathrm{X} \\
{[12,21]}\end{array}$ \\
\hline & $\begin{array}{l}\text { Idea collection in predefined } \\
\text { categories }\end{array}$ & $\mathrm{X}$ & $\begin{array}{c}X \\
{[27,32]}\end{array}$ \\
\hline & $\begin{array}{l}\text { List of ideas organized in sub- } \\
\text { categories }\end{array}$ & $\mathrm{X}$ & \\
\hline & $\begin{array}{l}\text { Team interaction to promote } \\
\text { shared mental models }\end{array}$ & $\mathrm{X}$ & $\begin{array}{c}X \\
{[15,21,24,37]}\end{array}$ \\
\hline & $\begin{array}{l}\text { Created participative safety } \\
\text { and enabling minority dissent } \\
\text { to widen perspectives }\end{array}$ & & $\begin{array}{c}X \\
{[10,13,14,21,} \\
26]\end{array}$ \\
\hline & $\begin{array}{l}\text { Identification of the most } \\
\text { relevant ideas }\end{array}$ & $\mathrm{X}$ & \\
\hline & $\begin{array}{l}\text { List of categorized, elaborated } \\
\text { and weighted ideas }\end{array}$ & $\mathrm{X}$ & \\
\hline
\end{tabular}

\subsection{Task decomposition}

In the second step of the design approach, the collaboration process is decomposed into a sequence of activities. These activities are derived from the group products that have been identified in the previous step. The decomposition requires that by executing an activity, the corresponding group product is accomplished [23, 43]. Accordingly, we developed an initial outline of the collaborative process in two successive steps. First, we derived activities from the group products. Second, we sequenced these activities by considering their respective inputs and outputs. For example, the contribution of ideas in predetermined categories is a prerequisite for the idea collection in categories, which again is a prerequisite for identifying subcategories (see Table 1). Subsequently, following Kolfschoten and de Vreede [23], we assigned patterns of collaboration (PoC) to each of the activities to further decompose the process. PoCs describe the nature of a group's collaborative behavior with six established patterns: generate, reduce, clarify, organize, evaluate and build consensus [8, 23]. 


\subsection{Task-thinkLet choice}

The third step comprises the assignment of thinkLets to the developed activities in the preceding step. In CE, thinkLets represent documented and transferable building blocks for composing collaborative processes. For each of these thinkLets usage rules, conditions, restrictions, scripts and a pattern of collaboration are specified $[7,8]$. In order to select the appropriate thinkLets, which match the previously identified activities, we utilized the catalogue of available thinkLets from Briggs and de Vreede [7]. We structured this selection process by considering thinkLets, which correspond to the patterns of collaboration that have previously been assigned to the activities.

\subsection{Agenda building}

In the fourth step of the CoPDA, a detailed agenda is developed. This agenda building entails the adaptation of the selected thinkLets to the specific collaboration process. Furthermore, for each activity the following information should be indicated: name and duration of the activity, the group product that needs to be accomplished, the utilized thinkLet with the corresponding pattern of collaboration, scripted instructions including relevant questions and finally the required (ICT) tool to conduct the activity [23, 43]. Consequently, we developed an initial but comprehensive agenda that, in addition to the aforementioned information, includes the specification of the group formation for each activity. The agenda differentiates between instructions for the host, who presents relevant content to the plenary in the beginning and at the end of the workshop, and the practitioners, who each guide a group consisting of six to ten citizens through the process. In parallel to the agenda development, we determined the functionalities of a group support system (GSS), which is required to execute the process steps. To complete the third activity, a brainstorming feature is needed. In activity four and five an organizing functionality is required to categorize ideas. Lastly, to conduct activity seven a voting feature is necessary. The developed agenda was subject to minor revisions in the following step of the CoPDA, the design validation. The final version of the agenda is presented in Table 2.

\section{Design validation}

In the fifth step of the CoPDA, the designed collaborative process is validated. This evaluation is conducted to assess the general quality of the collaboration process. More precisely, the objective is to reveal weaknesses and verify that the pre-determined goal and group products from the first step are accomplished. To ensure a thorough design validation, different methods can be applied, e.g. simulation, expert evaluation, walk-throughs and pilot testing [23, 43].

To complete the design cycle, we performed a multi-method evaluation by iteratively assessing the collaboration process in six phases. To ensure a continuous improvement of the process, we utilized: three design simulations, one expert evaluation and one walk-through. After each evaluation phase, adjustments to the process and agenda had been applied (see Figure 1). Lastly, we conducted a pilot study to determine the satisfaction of participants with the process, its outcome and the perceived difficulty of the process and the utilized tool. Additionally, we analyzed the outcome of the process in terms of quantitative dimensions.

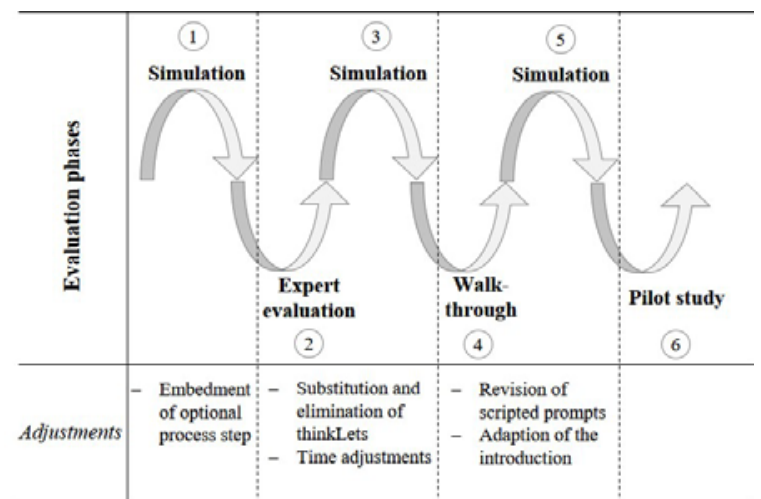

Figure 1. Design validation steps adapted from Sein et al. [39]

The first phase of the validation was a design simulation. With this method, the collaboration engineer tests the consistency of a collaborative process [23]. Therefore, we simulated the process step-by-step. As a result, we identified a missing activity (activity 4a), which, depending on the intermediate outcomes, can optionally improve the process. In the second phase, we consulted a collaboration expert to detect possible inefficient and alternative building blocks [23]. Thereby, we were able to substitute and eliminate thinkLets. We substituted a RichRelations block with an Evolution thinkLet (activity 4). Additionally, we removed a PopcornSort thinkLet. Furthermore, we identified shortcomings in relation to the temporal specifications (activity 3). In this way, we optimized the required collaborative working-style to accomplish the task. Thereafter, these adjustments were adopted and simulated in the third phase. The fourth phase addressed a walk-through. In CE, walk-throughs are applied to assess the process with practitioners and pro- 
Table 2. Final agenda (with revised sections in italic)

\begin{tabular}{|c|c|c|c|c|c|c|}
\hline $\begin{array}{c}\text { Activity/ } \\
\text { Time }\end{array}$ & $\begin{array}{c}\text { Group } \\
\text { formation }\end{array}$ & Activity description & Group products & \begin{tabular}{c|c|} 
PoC/ \\
thinkLet
\end{tabular} & Instructions & Tools \\
\hline \multicolumn{7}{|c|}{ Invitation of citizens, set-up virtual collaboration space, arrangements at the workshop location (sufficient number of tables and laptops) } \\
\hline 1/ 15 min. & $\begin{array}{l}\text { Plenary } \\
\text { group }\end{array}$ & $\begin{array}{l}\text { Explanation of work- } \\
\text { shop topic and proce- } \\
\text { dure }\end{array}$ & $\begin{array}{l}\text { Created vision and shared un- } \\
\text { derstanding of the procedure }\end{array}$ & Clarify & $\begin{array}{l}\text { Host welcomes the citizens to the workshop and introduces him/herself; presents the prepared case; explains the } \\
\text { overarching objective of the workshop and emphasizes the intended use of the obtained idea lists. } \\
\text { Say this: 1) The objective of this workshop is to gain a summary of elaborated, evaluated and categorized ideas } \\
\text { from citizens on the presented case. The results will be transferred to the administration in order to enrich the } \\
\text { decision-making procedure. } \\
\text { 2) Please choose a table and try to split into groups of at least } 6 \text { but no more than } 10 \text { members with heterogene- } \\
\text { ous backgrounds. }\end{array}$ & Presentation \\
\hline 2/ 10 min. & $\begin{array}{l}\text { Table } \\
\text { group }\end{array}$ & $\begin{array}{l}\text { Description of the } \\
\text { task }\end{array}$ & $\begin{array}{l}\text { Created goal interdependence } \\
\text { and support for innovation }\end{array}$ & Clarify & Practitioner clarifies the tasks and the interdependent work style; explains the handling of the collaboration tool. & Laptop \\
\hline 3/ 15 min. & Individual & $\begin{array}{l}\text { Contribution of ideas } \\
\text { to preferred discus- } \\
\text { sion topics }\end{array}$ & $\begin{array}{l}\text { Idea collection in predefined } \\
\text { categories }\end{array}$ & $\begin{array}{l}\text { Generate/ } \\
\text { LeafHopper }\end{array}$ & $\begin{array}{l}\text { Table members brainstorm on predefined categories and can switch between them. Practitioner describes the } \\
\text { desired characteristics of the generated ideas (title, self-explanatory and constructive), instructs members on } \\
\text { how to navigate through the categories and shows an example idea. } \\
\text { Say this: 1) Start working on the topics in which you have the most interest or the most expertise. } \\
\text { 2) You may not have time to work on every topic, so work first on the topics that are most important to you. }\end{array}$ & $\begin{array}{l}\text { Laptop; } \\
\text { GSS - brain- } \\
\text { storming } \\
\text { function }\end{array}$ \\
\hline 4/ $10 \mathrm{~min}$. & $\begin{array}{l}\text { Subgroup } \\
\text { at tables }\end{array}$ & $\begin{array}{l}\text { Identification of sub- } \\
\text { categories by organ- } \\
\text { izing and placing } \\
\text { ideas }\end{array}$ & $\begin{array}{l}\text { List of ideas organized in sub- } \\
\text { categories }\end{array}$ & $\begin{array}{l}\text { Organize/ } \\
\text { Evolution }\end{array}$ & $\begin{array}{l}\text { Practitioner assigns } 2-3 \text { table members into teams to work on a category. Teams simultaneously create subcate- } \\
\text { gories by defining a title and placing related ideas into them. } \\
\text { Ask/Say this: 1) How can we organize the ideas in the discussion topic into subcategories? We need groups of } \\
\text { 2-3 for this activity. Who wants to work on “category 1"? This assignment of ideas is preliminary - it will be } \\
\text { discussed with all group members afterwards. } \\
\text { 2) Please, indicate a title and place the ideas per drag-and-drop into the new subcategory. Please note, do not } \\
\text { make the subcategories too specific nor too general. }\end{array}$ & $\begin{array}{l}\text { Laptop; } \\
\text { GSS - organiz- } \\
\text { ing function }\end{array}$ \\
\hline $\begin{array}{l}\text { Opt.: } \\
4 \text { a/ } 5 \text { min. }\end{array}$ & $\begin{array}{l}\text { Table } \\
\text { group }\end{array}$ & \begin{tabular}{|l|} 
Revision of subcate- \\
gories by merging \\
similar subcategories
\end{tabular} & \begin{tabular}{|l|} 
Reduced number of subcatego- \\
ries with corresponding lists of \\
ideas
\end{tabular} & $\begin{array}{l}\text { Organize/ } \\
\text { RichRelations }\end{array}$ & $\begin{array}{l}\text { In case too many or redundant subcategories were created the practitioner supports a joint reexamination of ti- } \\
\text { tles in order to merge similar subcategories. } \\
\text { Say this: Please find two or more subcategories that are related in some way and tell me their relationship. }\end{array}$ & $\begin{array}{l}\text { Laptop; } \\
\text { GSS - organiz- } \\
\text { ing function }\end{array}$ \\
\hline $5 / 20 \mathrm{~min}$. & $\begin{array}{l}\text { Table } \\
\text { group }\end{array}$ & $\begin{array}{l}\text { Joint validation of } \\
\text { ideas in each subcat- } \\
\text { egory }\end{array}$ & $\begin{array}{l}\text { Team interaction to promote } \\
\text { shared mental models }\end{array}$ & $\begin{array}{l}\text { Clarify/ } \\
\text { BucketWalk }\end{array}$ & $\begin{array}{l}\text { Practitioner fosters the interaction between table members by guiding through a validation process for the ideas } \\
\text { in each subcategory in turn. Wrongly placed, redundant and poorly formulated ideas are edited and re-placed. } \\
\text { Ask/Say this: 1) Is there anything in this bucket, which does not belong here? If you think so, raise your hand, } \\
\text { and we will discuss where to put it. } \\
\text { 2) Are there items in this bucket, which you feel are as good as describing the same idea? If you think so, please } \\
\text { raise your hand. } \\
\text { 3) Are there items in this bucket, which you feel are poorly formulated? If you think so, raise your hand. }\end{array}$ & $\begin{array}{l}\text { Laptop; } \\
\text { GSS - organiz- } \\
\text { ing function }\end{array}$ \\
\hline 6/ 7 min. & $\begin{array}{l}\text { Table } \\
\text { group }\end{array}$ & $\begin{array}{l}\text { Voice individual } \\
\text { opinions on relevant } \\
\text { ideas }\end{array}$ & $\begin{array}{l}\text { Created participative safety and } \\
\text { enabling minority dissent to } \\
\text { widen perspectives. }\end{array}$ & $\begin{array}{l}\text { Generate/ } \\
\text { TheLobbyist }\end{array}$ & $\begin{array}{l}\text { Practitioner facilitates the verbal expression of each table members' most important idea in turn in order to guar- } \\
\text { antee participative decision-making. Only constructive feedback is allowed. } \\
\text { Say this: 1) Before each of you evaluates the ideas in the categories let us see which ones you find most im- } \\
\text { portant. } \\
\text { 2) You may express your personal preference as follows: Each of you may argue in favor of one of the ideas on } \\
\text { the list for } 30 \text { seconds - you are not allowed to criticize any of the ideas. } \\
\text { 3) If the idea that you prefer has already been argued for, say "I pass". }\end{array}$ & Laptop \\
\hline 7/ 5 min. & Individual & $\begin{array}{l}\text { Vote on ideas in sub- } \\
\text { categories }\end{array}$ & $\begin{array}{l}\text { Identification of most relevant } \\
\text { ideas }\end{array}$ & $\begin{array}{l}\text { Evaluate/ } \\
\text { StrawPoll }\end{array}$ & $\begin{array}{l}\text { Practitioner prompts members at the table to read the ideas in each subcategory. Table members are then asked } \\
\text { to individually assign } 5 \text { points to the most preferred ideas in each category. }\end{array}$ & $\begin{array}{l}\text { Laptop; GSS - } \\
\text { voting function }\end{array}$ \\
\hline 8/ $10 \mathrm{~min}$. & $\begin{array}{l}\text { Plenary } \\
\text { group }\end{array}$ & \begin{tabular}{|l|} 
Presentation of Top 5 \\
ideas over all topics \\
per table group
\end{tabular} & $\begin{array}{l}\text { List of categorized, elaborated } \\
\text { and weighted ideas }\end{array}$ & Clarify & $\begin{array}{l}\text { Practitioner pastes the ideas with the most points into a prepared presentation template. Host presents the ideas } \\
\text { in front of the plenary group. }\end{array}$ & Presentation \\
\hline $9 / 3$ min. & $\begin{array}{l}\text { Plenary } \\
\text { group }\end{array}$ & $\begin{array}{l}\text { Announcements and } \\
\text { send-off }\end{array}$ & & & $\begin{array}{l}\text { Host expresses gratitude for citizens' participation in the workshop. Formulates the intended use of the work- } \\
\text { shop results ("will be considered in the administrative decision-making process") and makes announcements. }\end{array}$ & Presentation \\
\hline
\end{tabular}


blem owners. This evaluation method helps to determine the quality of the expected outcome and pinpoint pitfalls concerning the facilitation [23]. We conducted the walk-though with a practitioner, a professional facilitator and stakeholders from a municipal institution. This feedback was used to revise scripted prompts in the agenda (e.g. activity 1). Furthermore, we adapted the introduction to the process. In phase five, these changes were adopted and the consistency of the improved process was tested with a design simulation. The last step of the validation addressed the assessment of the revised process with a pilot study. For this evaluation the final agenda (see Table 2) was utilized.

\subsection{Pilot study — Outline}

We evaluated the process design with an experimental pilot study comprising two analyses. In both evaluation settings, the designed e-participation workshop process was compared to an expert facilitated citizen participation workshop format, serving as a control condition. In a first step, the workshop processes were examined by means of a questionnaire. That is, the satisfaction of participants with the two processes and its outcomes were assessed. In addition, the comprehensibility of the two processes and the perceived difficulty of the utilized tools were analyzed. In a second step, we evaluated the quantitative characteristics of the two processes' outcomes.

Experimental setting: Twenty-six master's students in (business) information systems simultaneously took part in four workshop sessions. They had no experience with citizen participation, but most of them were familiar with groupware and partly with workshop situations in general (e.g. design thinking). The participants were randomly assigned to the four groups before the start of the sessions. Two groups followed the engineered process design, using a GSS (MeetingSphere). Both treatment groups were facilitated by a collaboration engineer. Treatment group 1 (CE 1) had eight participants and treatment group 2 (CE 2) seven participants. In addition, the collaboration engineers were assisted by a facilitator who controlled the tool according to the process agenda. In addition, two control groups were formed, consisting of five (Control 3) and six participants (Control 4). Each control group workshop was prepared and conducted separately by an expert from a municipal institution, in accordance with their usual practices from citizen participation workshops. The same subject area and meeting length applied to all four groups. Before the participants were divided into the different groups, one of the experts introduced them to the problem area. The aim was to create a well-developed setting as close to reality as possible. Therefore, a scenario from an actual planning process was taken up and presented to all participants by the experts.

Questionnaire: After the end of the group sessions, each participant completed a questionnaire. A modified version of the General Meeting Assessment Survey from Briggs et al. [6] was utilized. In total, the questionnaire comprised four scales: 1) satisfaction with the workshop process (SWP), 2) satisfaction with the workshop outcome (SWO), 3) process difficulty (PD) and 4) tool difficulty (TD). Each of these scales consisted of five items with a five-point Likert-type scale.

Quantitative outcome analysis: To analyze the outcome of the four groups (CE 1, CE 2, Control 3 and Control 4) the generated ideas were investigated. In both treatment groups, the ideas were collected via the GSS. The outcome of the control groups was captured with paper and pencil. The quantitative assessment included the overall number of ideas, the number of formed subcategories and the average number of words per idea for each group.

\subsection{Pilot study - Results}

Questionnaire: The intention of the statistical analysis was to assess, whether the design of the e-participation workshop process delivers comparable ratings in relation to the participants' satisfaction (SWP and SWO) and their perceptions of the process and tool (PD and TD) in comparison to an expert citizen participation workshop process.

First, the internal consistency of the questionnaire items with reference to their corresponding scale was computed. Second, in order to compare the workshop processes, a statistical test for group comparison was performed. For this reason, the collected data from the four groups were matched to the conditions "CE" and "Control” respectively. Furthermore, analyses concerning the descriptive statistics (median, mean and standard deviation) were conducted.

The internal consistency reliability of the utilized scales, tested with Cronbach's alpha coefficient (see Table 3), proved to be good (SWP, SWO and TD) or at least acceptable (PD) [38]. Consequently, none of the items had to be excluded. Due to the appearance of non-normal distributions, a nonparametric test was utilized to compare the participants' ratings in relation to the two conditions. Therefore, the Wilcoxon-MannWhitney test was performed to assess whether the processes achieved similar scores concerning the four rating dimensions (SWP, SWO, PD and TD). For each scale, the test statistic showed a significant result, which indicates disparate ratings for the two processes (see Table 3). 
Table 3. Descriptive statistics, Cronbach's alpha and Wilcoxon-Mann-Whitney test (WMW) $\left(p<0.05^{*}\right)$

\begin{tabular}{|c|c|c|c|c|}
\hline \multirow{2}{*}{ Scale } & \multirow{2}{*}{$\begin{array}{c}\text { Cron- } \\
\text { bach's } \\
\text { alpha }\end{array}$} & $\begin{array}{c}\mathrm{CE} \\
(\mathrm{n}=15)\end{array}$ & $\begin{array}{l}\text { Control } \\
(n=11)\end{array}$ & \multirow{2}{*}{ WMW } \\
\hline & & \multicolumn{2}{|c|}{$\begin{array}{c}\text { Median } \\
\text { Mean }(S D)\end{array}$} & \\
\hline SWP & .86 & $\begin{array}{c}4.20 \\
4.23(.65)\end{array}$ & $\begin{array}{c}5.00 \\
4.71(.45)\end{array}$ & $161.50 *$ \\
\hline SWO & .90 & $\begin{array}{c}3.80 \\
3.65(.97)\end{array}$ & $\begin{array}{c}4.60 \\
4.51(.47)\end{array}$ & $157.50 *$ \\
\hline PD & .75 & $\begin{array}{c}4.00 \\
4.03(0.55)\end{array}$ & $\begin{array}{c}4.60 \\
4.53(0.36)\end{array}$ & $157.00 *$ \\
\hline TD & .87 & $\begin{array}{c}3.80 \\
3.64(.50)\end{array}$ & $\begin{array}{c}4.80 \\
4.87(.13)\end{array}$ & $120.50 *$ \\
\hline
\end{tabular}

Quantitative outcome analysis: To ensure the comparability of the workshop outcomes, the pre-given example ideas in the CE groups were eliminated prior to the analysis. Additionally, it should be noted that similar ideas were not necessarily identified and cleared up in the control groups, in contrast to the CE groups, in which this was a distinct process step.

The results of the analysis of the workshop outcomes (see Table 4) show that more ideas were generated in each of the traditional formats than in the groups following the CE process design. For structuring the previously generated ideas, the participants of both CE groups formed a higher number of subcategories in comparison to the control groups. Looking at the average length of the ideas, the CE groups with 14.31 and 15.15 words respectively utilized more words than the two control groups (2.77 and 2.92).

Table 4. Analysis of workshop outcomes

\begin{tabular}{|c|c|c|c|c|}
\hline Outcomes & $\begin{array}{c}\mathrm{CE} \\
1\end{array}$ & $\begin{array}{c}\text { CE } \\
2\end{array}$ & $\begin{array}{c}\text { Control } \\
3\end{array}$ & $\begin{array}{c}\text { Control } \\
4\end{array}$ \\
\hline Ideas & 36 & 27 & 44 & 50 \\
\hline Subcategories & 16 & 12 & 10 & 9 \\
\hline $\begin{array}{l}\text { Average number } \\
\text { of words per idea }\end{array}$ & 14.31 & 15.15 & 2.77 & 2.92 \\
\hline
\end{tabular}

\section{Discussion and conclusion}

The overarching objective of our research was to systematically create and evaluate an e-participation workshop process design, by specifying how to integrate ICT into the traditional civic participation format of workshops, which thereby has the potential to constitute an implementable and recurring instrument in a multi-instrumental e-participation strategy [45].
Accordingly, we applied the three cycles within the DSR framework in combination with the systematic design approach of CE to develop and evaluate the e-participation workshop process, which incorporates relevant theoretical and practical requirements as well as distinct facilitating factors for group creativity.

As part of the design cycle, the evaluation of the eparticipation workshop provides manifold findings. The quantitative outcome analysis showed that on average participants in the e-participation workshop used more words to describe their ideas in comparison to participants in the expert workshop. This result indicates that a large proportion of the contextual knowledge can be preserved by continuously and automatically documenting ideas with ICT in a parallel and efficient way, while simultaneously reducing the workshop facilitators' cognitive load to capture the generated content. Apart from that, the descriptive statistics of the questionnaire analysis illustrate that participants in the e-participation workshop conditions were satisfied with the e-participation workshop process itself $(M d n=4.20)$ and with the outcome $(M d n=$ 3.80). Furthermore, the results demonstrate that the subjects perceived the workshop process $(M d n=4.00)$ and tool difficulty $(M d n=3.80)$ to be comprehensible. Although the questionnaire analysis revealed that the e-participation workshop did not deliver the same results as the expert workshop, the obtained results exemplify the useful outcome and illustrate the practicability of the designed e-participation workshop. With respect to these results, we attained our research goals. First, we show an applicable solution for incorporating ICT into a civic participation workshop by systematically developing a process design with the CoPDA and thinkLets [7, 23]. This blueprint enables public authorities to repeatedly conduct e-participation workshops. Second, the successful ICT-integration allows a seamless transfer of the input generated during these workshops across other participation instruments.

Besides these promising results, there are a few limitations to consider. First, with reference to the experimental implementation, it should be noted that the groups consisted of information systems students. Therefore, the participants' experience with ICT might have positively affected the execution of activities. To counteract the potential influence of citizens' ICTrelated capabilities on the workshop process, the design includes a detailed explanation of the tool for less experienced individuals. Second, we created a realistic scenario that was professionally presented by experts. Nevertheless, the experimental setting might not have created a personal concern that sometimes prevails in real-world situations and can lead to strong emotions during a discussion. Hence, a comparable level of 
arousal and motivation might not have been provoked in the participants.

Due to the aforementioned limitations, in future research, the e-participation workshop process should be implemented and tested in a real-life setting with a heterogeneous sample of citizens. This assessment should also explore, whether practitioners are able to execute the process without involvement of the designers. Furthermore, in addition to the quantitative characteristics, the quality of the generated ideas could be evaluated by experts, i.e. in terms of novelty and usefulness.

Our research contributes scientific insights via the rigor cycle and practical implications in the field of digital government, particularly civic e-participation, via the relevance cycle, by means of the validated eparticipation workshop process design. On the one hand, the created e-participation workshop constitutes a promising instrument for public authorities, which pursue a multi-instrumental e-participation strategy. That is, by digitally capturing citizens' input in a central database for different e-participation instruments [45], the information provision to the public could be enhanced and the possibility for citizens to engage more intensively in co-creation via different channels is ensured. On the other hand, the well-documented process supports domain-specific practitioners to conduct an ICT-mediated citizen participation workshop without professional facilitation capabilities.

With our evolved artefact, the e-participation workshop process design, we have completed the rigor cycle by adding prescriptive knowledge to the knowledge base [18]. The created blueprint can be used by researchers to inform their future design activities. Additionally, we contribute to e-participation literature by presenting CE as a suitable approach to systematically incorporate ICT as a solution to overcome specific shortcomings of traditional civic participation workshops.

\section{References}

[1] Afzalan, N., T.W. Sanchez, and J. Evans-Cowley, "Creating Smarter Cities: Considerations for Selecting Online Participatory Tools", Cities, 67, 2017, pp. 21-30.

[2] Ali, H., L. Macaulay, and L. Zhao, "A Collaboration Pattern Language for e-Participation: A Strategy for Reuse", 9th European Conference on e-Government, London, UK, 29-30 June. 2009.

[3] Amabile, T.M., "A Model of Creativity and Innovation in Organizations", Research in Organizational Behavior, 10(1), 1988, pp. 123-167.

[4] Bittner, E.A.C. and J.M. Leimeister, "Creating Shared Understanding in Heterogeneous Work Groups: Why It Matters and How to Achieve It", Journal of Management Information Systems, 31(1), 2014, pp. 111-144.
[5] Brabham, D.C., "Crowdsourcing the Public Participation Process for Planning Projects", Planning Theory, 8(3), 2009, pp. 242-262.

[6] Briggs, R.O., G.L. Kolfschoten, G.-J. de Vreede, S. Lukosch, and C.C. Albrecht, "Facilitator-in-a-Box: Process Support Applications to Help Practitioners Realize the Potential of Collaboration Technology", Journal of Management Information Systems, 29(4), 2013, pp. 159-194.

[7] Briggs, R.O. and G.-J. de Vreede, ThinkLets: Building Blocks for Concerted Collaboration, Omaha, 2009.

[8] Briggs, R.O., G.-J. de Vreede, G.L. Kolfschoten, and D.L. Dean, "Defining Key Concepts for Collaboration Engineering", 12th Americas Conference on Information Systems, Acapulco, Mexico, 04-06 August. 2006.

[9] Brody, S.D., D.R. Godschalk, and R.J. Burby, "Mandating Citizen Participation in Plan Making: Six Strategic Planning Choices", Journal of the American Planning Association, 69(3), 2003, pp. 245-264.

[10] Burke, C.S., K.C. Stagl, E. Salas, L. Pierce, and D. Kendall, "Understanding Team Adaptation: A Conceptual Analysis and Model", Journal of Applied Psychology, 91(6), 2006, pp. 1189-1207.

[11] Callahan, K., "Citizen Participation: Models and Methods", International Journal of Public Administration, 30(11), 2007, pp. 1179-1196.

[12] Courtright, S.H., G.R. Thurgood, G.L. Stewart, and A.J. Pierotti, "Structural Interdependence in Teams: An Integrative Framework and Meta-Analysis", Journal of Applied Psychology, 100(6), 2015, pp. 1825-1846.

[13] Dreu, C.K.W. de, "Team Innovation and Team Effectiveness: The Importance of Minority Dissent and Reflexivity", European Journal of Work and Organizational Psychology, 11(3), 2002, pp. 285-298.

[14] Dreu, C.K.W. de and M.A. West, "Minority Dissent and Team Innovation: The Importance of Participation in Decision Making", Journal of Applied Psychology, 86(6), 2001, pp. 1191-1201.

[15] Edmondson, A.C. and J.-F. Harvey, "Cross-Boundary Teaming for Innovation: Integrating Research on Teams and Knowledge in Organizations", Human Resource Management Review, 28(4), 2018, pp. 347-360.

[16] Fedotova, O., L. Teixeira, and H. Alvelos, "E-participation in Portugal: Evaluation of Government Electronic Platforms", Procedia Technology, 5, 2012, pp. 152-161.

[17] Fung, A., "Putting the Public Back into Governance: The Challenges of Citizen Participation and Its Future", Public Administration Review, 75(4), 2015, pp. 513-522.

[18] Gregor, S. and A.R. Hevner, "Positioning and Presenting Design Science Research for Maximum Impact", MIS Quarterly, 37(2), 2013, pp. 337-355.

[19] Hackman, J.R., "The Design of Work Teams", in Handbook of Organizational Behavior, J.W. Lorsch, Editor. 1987. Prentice-Hall: Englewood Cliffs, N.J.

[20] Hevner, A.R., "A Three Cycle View of Design Science Research", Scandinavian Journal of Information Systems, 19(2), 2007, pp. 87-92. 
[21] Hülsheger, U.R., N. Anderson, and J.F. Salgado, "Team-Level Predictors of Innovation at Work: A Comprehensive Meta-Analysis Spanning Three Decades of Research", Journal of Applied Psychology, 94(5), 2009, pp. 1128-1145.

[22] IAP2, "Public Participation Pillars", Available at: https://c.ymcdn.com/sites/iap2.site-ym.com/rsource/resmgr/ files/IAP2_Federation_-_P2_Pillars.pdf (Accessed: May 2018).

[23] Kolfschoten, G.L. and G.-J. de Vreede, "A Design Approach for Collaboration Processes: A Multimethod Design Science Study in Collaboration Engineering", Journal of Management Information Systems, 26(1), 2009, pp. 225256.

[24] Mathieu, J.E., T.S. Heffner, G.F. Goodwin, E. Salas, and J.A. Cannon-Bowers, "The Influence of Shared Mental Models on Team Process and Performance", Journal of Applied Psychology, 85(2), 2000, pp. 273-283.

[25] Medaglia, R., "eParticipation Research: Moving Characterization Forward (2006-2011)", Government Information Quarterly, 29(3), 2012, pp. 346-360.

[26] Nijstad, B.A., F. Berger-Selman, and C.K.W. de Dreu, "Innovation in Top Management Teams: Minority Dissent, Transformational Leadership, and Radical Innovations", European Journal of Work and Organizational Psychology, 23(2), 2014, pp. 310-322.

[27] Nijstad, B.A., W. Stroebe, and H.F.M. Lodewijkx, "Cognitive Stimulation and Interference in Groups: Exposure Effects in an Idea Generation Task", Journal of Experimental Social Psychology, 38(6), 2002, pp. 535-544.

[28] OECD, Citizens as Partners: OECD Handbook on Information, Consultation and Public Participation in PolicyMaking, OECD Publications, Paris, 2001.

[29] Pearce, C.L. and M.D. Ensley, "A Reciprocal and Longitudinal Investigation of the Innovation Process: The Central Role of Shared Vision in Product and Process Innovation Teams(PPITs)", Journal of Organizational Behavior, 25(2), 2004, pp. 259-278.

[30] Peristeras, V., G. Mentzas, K.A. Tarabanis, and A. Abecker, "Transforming E-government and E-participation through IT", IEEE Intelligent Systems, 24(5), 2009, pp. 1419.

[31] Quick, K.S. and J.R. Sandfort, "Learning to Facilitate: Implications for Skill Development in the Public Participation Field", in The Professionalization of Public Participation, L. Bherer, Editor. 2017. Taylor and Francis: London.

[32] Rietzschel, E.F., B.A. Nijstad, and W. Stroebe, "Relative Accessibility of Domain Knowledge and Creativity: The Effects of Knowledge Activation on the Quantity and Originality of Generated Ideas", Journal of Experimental Social Psychology, 43(6), 2007, pp. 933-946.

[33] Rodríguez-Bolívar, M.P., L. Alcaide-Muñoz, and M.J. Cobo, "Analyzing the Scientific Evolution and Impact of eParticipation Research in JCR Journals Using Science Mapping", International Journal of Information Management, 40, 2018, pp. 111-119.
[34] Sæbø, Ø., J. Rose, and L. Skiftenes Flak, "The Shape of eParticipation: Characterizing an Emerging Research Area", Government Information Quarterly, 25(3), 2008, pp. 400428.

[35] Sanford, C. and J. Rose, "Characterizing eParticipation", International Journal of Information Management, 27(6), 2007, pp. 406-421.

[36] Sanoff, H., Community Participation Methods in Design and Planning, J. Wiley \& Sons, New York, 2000.

[37] Santos, C.M., S. Uitdewilligen, and A.M. Passos, "Why is Your Team More Creative Than Mine? The Influence of Shared Mental Models on Intra-group Conflict, Team Creativity and Effectiveness", Creativity and Innovation Management, 24(4), 2015, pp. 645-658.

[38] Schmidt, N., "Uses and Abuse of Coefficent Alpha", Psychological Assessment, 8(4), 1996, pp. 350-353.

[39] Sein, M.K., O. Henfridsson, S. Purao, M. Rossi, and R. Lindgren, "Action Design Research", MIS Quarterly, 35(1), 2011, p. 37.

[40] Tambouris, E., N. Liotas, D. Kaliviotis, and K. Tarabanis, "A Framework for Scoping eParticipation", 8th Annual International Digital Government Research Conference, Philadelphia, PA, USA, 20-23 May. 2007.

[41] Tambouris, E., N. Liotas, and K. Tarabanis, "A Framework for Assessing eParticipation Projects and Tools", 40th Hawaii International Conference on System Sciences, Waikoloa, HI, USA, 03-06 January. 2007.

[42] Vreede, G.-J. de and R.O. Briggs, "Collaboration Engineering: Reflections on 15 Years of Research \& Practice", 51st Hawaii International Conference on System Sciences, Waikoloa, HI, USA, 03-06 January. 2018.

[43] Vreede, G.-J. de, R.O. Briggs, and A.P. Massey, "Collaboration Engineering: Foundations and Opportunities", Journal of the Association for Information Systems, 10(3), 2009, pp. 121-137.

[44] Wimmer, M.A., "Ontology for an e-Participation Virtual Resource Centre", 1st International Conference on Theory and Practice of Electronic Governance, Macao, China, 10-13 December. 2007.

[45] Wirtz, B.W., P. Daiser, and B. Binkowska, "E-participation: A Strategic Framework", International Journal of Public Administration, 41(1), 2018, pp. 1-12.

[46] Woodman, R.W., J.E. Sawyer, and R.W. Griffin, "Toward a Theory of Organizational Creativity", The Academy of Management Review, 18(2), 1993, pp. 293-321.

[47] Yang, K. and S.K. Pandey, "Further Dissecting the Black Box of Citizen Participation: When Does Citizen Involvement Lead to Good Outcomes?", Public Administration Review, 71(6), 2011, pp. 880-892.

[48] Zolotov, M.N., T. Oliveira, and S. Casteleyn, "E-participation Adoption Models Research in the Last 17 Years: A Weight and Meta-Analytical Review", Computers in Human Behavior, 81, 2018, pp. 350-365. 